Journal of Advanced Research in Fluid Mechanics and Thermal Sciences

\title{
Effect of Different Types of Stenosis on Generalized Power Law Model of Blood Flow in a Bifurcated Artery
}

\author{
Muhammad Sabaruddin Ahmad Jamali ${ }^{1}$, Zuhaila Ismail ${ }^{1,}{ }^{*}$, Norsarahaida Saidina Amin ${ }^{1}$ \\ 1 Department of Mathematical Sciences, Faculty of Science, Universiti Teknologi Malaysia, 81310 Johor Bahru, Malaysia
}

\begin{tabular}{|c|c|}
\hline ARTICLE INFO & ABSTRACT \\
\hline $\begin{array}{l}\text { Article history: } \\
\text { Received } 19 \text { May } 2021 \\
\text { Received in revised form } 1 \text { September } 2021 \\
\text { Accepted } 5 \text { September } 2021 \\
\text { Available online } 4 \text { October } 2021\end{array}$ & $\begin{array}{l}\text { This study is focus on generalized power law model of blood flow in a stenosed } \\
\text { bifurcated artery under the effect of different types of stenosis. Stenosis can cause the } \\
\text { narrowing of the artery that may reduce the flow of blood supply to the heart, and this } \\
\text { may lead to the heart attacks. The geometry of the bifurcated artery with different } \\
\text { classification of stenosis locations is considered in order to shows four possible } \\
\text { morphologies formation of plaque from healthy artery to disease artery. The bifurcated } \\
\text { artery is modelled as a two-dimensional rigid wall since the wall of a disease artery is } \\
\text { reported to be less flexibility. Few assumptions are considered such as blood are } \\
\text { incompressible, laminar, steady and characterized as the generalized power-law model. } \\
\text { Simulation results are obtained using COMSOL Multiphysics } 5.2 \text {, which is a software } \\
\text { that based on the finite element method to solve this problem. Results concerning the } \\
\text { effect of different locations of stenosis on generalized power law model of the blood } \\
\text { flow characteristic such as streamlines pattern are discussed. }\end{array}$ \\
\hline
\end{tabular}

\section{Introduction}

Coronary artery disease is caused by atherosclerosis that occurred due to stenosis which formed as a result of fatty substances, cholesterol, cellular waste products, and smooth muscle cells accumulation on the arterial wall, [1]. Stenosis is a localize plaque that cause the narrowing on the vessel wall and causing an alternation in the flow structure which consequently reduced the fluid flow passing to the other organs and tissues, [2] As the plaque tend to rupture, an individual may suffer to the risk of cardiovascular disease such as heart attack and stroke. The fruitful study has been classified the geometry of bifurcated artery previously is according to the angulation between mother and daughter artery and according to the location of plaque. T- shaped bifurcated artery is classified when the angulation is $>70^{\circ}$ and plagued shifting to the bifurcation branched is more difficult, but for $Y$ - shaped bifurcated artery is more pronounced because the angulation of mother to daughter artery is $<70^{\circ}$, [3]. As the anatomical considerations, four different type of model has been considered in present study regarding to [3-6] to shows the plaque distribution morphologies.

\footnotetext{
* Corresponding author.

E-mail address: zuhaila@utm.my

https://doi.org/10.37934/arfmts.87.3.172183
} 
Furthermore, it has been confirmed that the Newtonian model is valid only when the shear rates is more than $100 \mathrm{~s}^{-1}$ (reciprocal seconds), which have a tendency to occur in big arteries only, [7-9]. Mostly, the non-Newtonian would be a more accurate depiction of blood flow in the arteries, especially for stenosed situations. The significant of Newtonian and non-Newtonian blood model such as Carreau model, Walburn-Schneck model, power law, Casson model and generalized power law model investigated by [10]. The studies of [11-14] are considered generalized power law model to investigate the influence of the stenoses shape on the characteristics of blood flow. [15] studied the shear-thickening and shear-thinning of the generalized power law model in an artery with different kinds of stenosis; cosine, smooth-shaped constrictions and irregular without any body force. The novelty in this study is the consideration of the rheological behaviour of blood that is characterized by using the generalized power law model which flowing through four different types of stenosis in a bifurcated artery from healthy to disease artery. Various locations of stenosis in the bifurcation artery give a huge considerable effect to the blood characteristic and flow structure. It is believed that the existence of flow recirculation in the cardiovascular system can cause danger to the health of a person, especially atherosclerosis patients since the blood is moving slowly in this zone. A numerical simulation is needed since the geometry of bifurcated artery itself is in irregular shape and small scale, thus COMSOL Multiphysics a software based on the finite element method (FEM) is proposed in this study to obtain the numerical results of flow.

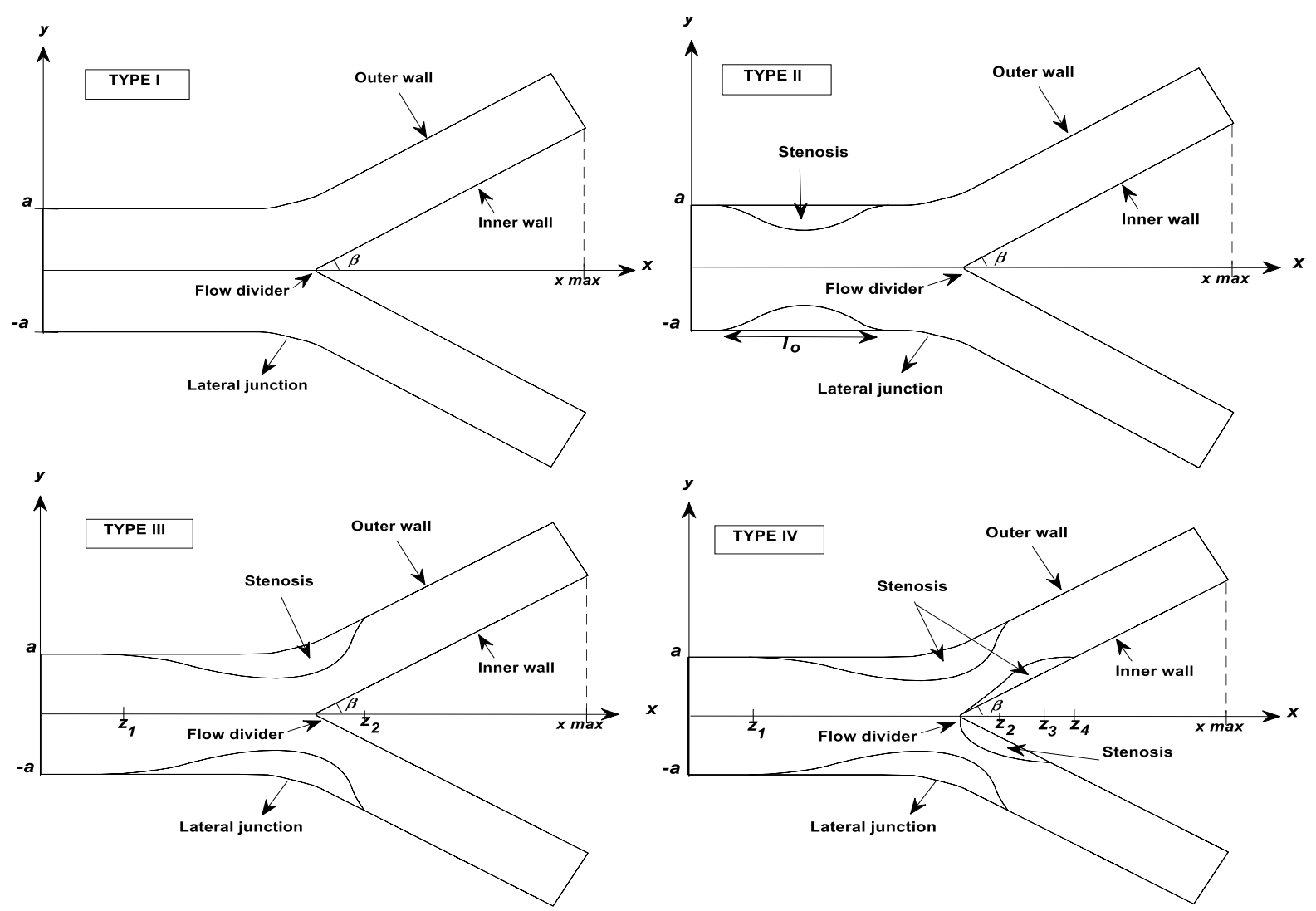

Fig. 1. Four different type of geometry model considered 


\section{Problem Formulation}

In order to formulate the computational domain for the stenosed bifurcated artery, these following assumptions are imposed: example

i. The artery forming bifurcation is of finite length.

ii. 4 possible morphologies considered from TYPE I to TYPE IV.

iii. Curvatures are introduced at the lateral junctions and the flow divider of the arterial bifurcation to ensure that one can rule out the presence of any discontinuity causing non-existent of separation zones.

\subsection{Model Construction}

Different classifications have been proposed and used to define these lesions [3-6]. Adding two models of a bifurcation (TYPE I and TYPE III) to shows the four possible morphologies as shown in Figure 1: TYPE I is no stenosis in bifurcated artery. TYPE II, stenosis involves in the parent artery proximal to bifurcation. TYPE III, stenosis located in the parent artery elongate into upper wall of bifurcation. TYPE IV, stenosis located in the parent vessel, proximal and ostium of bifurcation.

\subsection{Governing Equations}

The blood flow in the arterial bifurcation is considered to be in dimensionless, steady, laminar, and incompressible. The flowing blood is characterised by a generalized power law fluid model.

$$
\begin{aligned}
& \frac{\partial u}{\partial x}+\frac{\partial v}{\partial y}=0 . \\
& {\left[u \frac{\partial u}{\partial x}+v \frac{\partial u}{\partial y}\right]=-\frac{\partial p}{\partial x}+\frac{1}{\operatorname{Re}}\left(\frac{\partial \tau_{x x}}{\partial x}+\frac{\partial \tau_{x y}}{\partial y}\right) .} \\
& {\left[u \frac{\partial v}{\partial x}+v \frac{\partial v}{\partial y}\right]=-\frac{\partial p}{\partial y}+\frac{1}{\operatorname{Re}}\left(\frac{\partial \tau_{x y}}{\partial x}+\frac{\partial \tau_{y y}}{\partial y}\right)} \\
& \bar{\tau}=-\left\{m\left|\sqrt{\frac{1}{2}(\underline{\Delta}: \underline{\Delta})}\right|^{n-1}\right\} \underline{\Delta} \\
& \tau_{x x}=-2\left\{m\left|\left[\frac{1}{2}(\underline{\Delta}: \underline{\Delta})\right]^{1 / 2}\right|^{n-1}\right\}\left(\frac{\partial u}{\partial x}\right) \\
& \tau_{y y}=-2\left\{\left.m\left[\mid \frac{1}{2}(\underline{\Delta}: \underline{\Delta})\right]^{1 / 2}\right|^{n-1}\right\}\left(\frac{\partial u}{\partial y}\right)
\end{aligned}
$$




$$
\begin{aligned}
& \tau_{x y}=\tau_{y x}=-\left\{m\left|\left[\frac{1}{2}(\underline{\Delta}: \underline{\Delta})\right]^{1 / 2}\right|^{n-1}\right\}\left(\frac{\partial v}{\partial x}+\frac{\partial u}{\partial y}\right), \\
& \frac{1}{2}(\underline{\Delta}: \underline{\Delta})=\frac{1}{2} \sum_{i} \sum_{j}\left[\left(\frac{\partial v_{i}}{\partial x_{j}}+\frac{\partial v_{j}}{\partial x_{i}}\right)-\frac{2}{3}(\bar{\nabla} \cdot \bar{v}) \delta_{i j}\right]^{2},
\end{aligned}
$$

in which $i$ and $j$ take on the values $x, y$ and $\delta_{i j}=1$ for $i=j$. Reynolds number, Re:

$$
\operatorname{Re}=\frac{\rho u_{\infty} L}{\mu},
$$

where $\bar{\tau}$ is the stress tensor, $u$ is the axial velocity, $v$ is the radial velocity, $y$ is the radial coordinate and $x$ is axial coordinate. $\mu$ denotes the dynamic viscosity of blood, $\rho$ is the density of blood, $\operatorname{Re}$ is Reynold number and $p$ is the pressure distribution acting on the surface.

\subsection{Boundary Conditions}

At the inlet, a parabolic velocity profile is imposed as:

$$
u(x, y)=u_{\max }\left(1-\left(\frac{y}{a}\right)^{\frac{n+1}{n}}\right) \text { and } v(x, y)=0 \text {, at } x=0 \text {, and }-a \leq y \leq a .
$$

No-slip conditions along all the arterial walls:

$$
u(x, y)=0, v(x, y)=0
$$

A traction-free condition is applied at the outlet which can be stated as

$$
(-p \mathbf{I}+\tau) \cdot \mathbf{n}=0
$$

where $\mathbf{n}$ represents a unit outward normal vector with the pressure point constraint, $p=0$ being implemented at $x=0$ and $y=0.5$.

\section{Computational Mesh and Validation}

For the purpose of mesh dependency test and validation, geometry is used and constructed based on model proposed by [16] and [17]. Let $(x, y)$ be the coordinates of a material point. 


$$
R_{1}(x)=\left\{\begin{array}{l}
a, 0 \leq x \leq d, d+l_{0} \leq x \leq x_{1} \\
a-\frac{4 \tau_{m}}{l_{0}^{2}}\left(l_{0}(x-d)-(x-d)^{2}\right), d \leq x \leq d+l_{0} \\
a+r_{0}-\sqrt{r_{0}^{2}-\left(x-x_{1}\right)^{2}}, x_{1} \leq x \leq x_{2} \\
2 r_{1} \sec \beta+\left(x-x_{2}\right) \tan \beta, x_{2} \leq x \leq x_{\text {max }}-s
\end{array} \quad R_{2}(x)=\left\{\begin{array}{ll}
0, & 0 \leq x \leq x_{3}, \\
\sqrt{r_{0}^{\prime}-\left(x-\left(x_{3}+r_{0}^{\prime}\right)\right)^{2}}, & x_{3} \leq x \leq x_{4}, \\
r_{0}^{\prime} \cos \beta+\left(x-x_{4}\right) \tan \beta, x_{4} \leq x \leq x_{\max },
\end{array}\right\},\right.
$$

where $R_{1}(x)$ and $R_{2}(x)$ represent the radii of the outer and inner wall, respectively. Meanwhile, $a$ and $r_{1}$ are the respective radii of the mother and daughter artery. $r_{0}$ and $r_{0}$ are the radii of curvature for the lateral junction and the flow divider, respectively. Whereas, $l_{0}$ is the length of the stenosis at a distance $d$ from the origin. Location of the onset and offset of the lateral junction are denoted by $x_{1}$ and $x_{2}$ respectively. $x_{3}$ indicated as the apex, $\tau_{m}$ represents the maximum height of stenosis occur at $d+l_{0} / 6$ and $d+5 l_{0} / 6$ while $\beta$ denote half of the bifurcation angle. Parameters involved in the above expressions may be given as

$x_{2}=x_{1}+r_{0} \sin \beta, r_{0}=\left(a-2 r_{1} \sec \beta\right) /(\cos \beta-1), r_{0}^{\prime}=\left(x_{3}-x_{2}\right) \sin \beta / 1-\sin \beta$.

$x_{3}=x_{2}+q, s=2 r_{1} \sin \beta, x_{4}=x_{3}+r_{0}^{\prime}(1-\sin \beta)$.

The dimensional data for validation purpose have been made use from [16] and [17]:

$a=0.0075 \mathrm{~m}, \quad l_{0}=0.015 \mathrm{~m}, \quad d=0.005 \mathrm{~m}, \quad x_{\max }=0.06 \mathrm{~m}, \quad x_{1}=0.025 \mathrm{~m}, \quad \rho=1050 \mathrm{kgm}^{-3}, \mu=0.0035 \mathrm{Pas}^{-1}$, $\beta=30^{\circ}, q=0.002 \mathrm{~m}, \quad r_{1}=0.51 a, l_{0}=0.015 \mathrm{~m}, \quad d=0.005 \mathrm{~m}, x_{\max }=0.06 \mathrm{~m}, x_{1}=0.025 \mathrm{~m}$.

\section{Table 1}

Mesh parameters computed in COMSOL Multiphysics and MATLAB

\begin{tabular}{llll}
\hline Software & Parameter & $\begin{array}{l}\text { Domain } \\
\text { elements }\end{array}$ & $\begin{array}{l}\text { Maximum velocity } \\
\text { (m/s) }\end{array}$ \\
\hline \multirow{3}{*}{ Present study, COMSOL } & Mesh 1 & 22739 & 0.13466 \\
& Mesh 2 & 23002 & 0.13487 \\
& Mesh 3 & 23420 & 0.13489 \\
& Mesh 4 & 23962 & 0.13498 \\
& Mesh 5 & 24924 & 0.13501 \\
\hline
\end{tabular}

All computations were performed on a personal computer running 64-bit Windows 8 with speed of $1.70 \mathrm{GHz}$ and a RAM of $9.89 \mathrm{~GB}$. The geometry was drawn by means of the built-in CAD tools. Then the built-in meshing function was used to generate unstructured triangular elements of the model. Several attempts of mesh are performed in COMSOL Multiphysics to ensure the results obtained are not depending on the mesh parameters, see Figure 2. The number of domain elements and maximum velocity computed using COMSOL Multiphysics in present study are summarised in Table 1 . Based on the mesh dependency test demonstrated from Table 1 and Figure 3, maximum velocity in range between Mesh 2 and Mesh 3 are nearly identical with domain element 18400 and 19531 respectively. In order to reduce computational time, mesh 2 is selected in order to provide a satisfactory solution to our problem. 

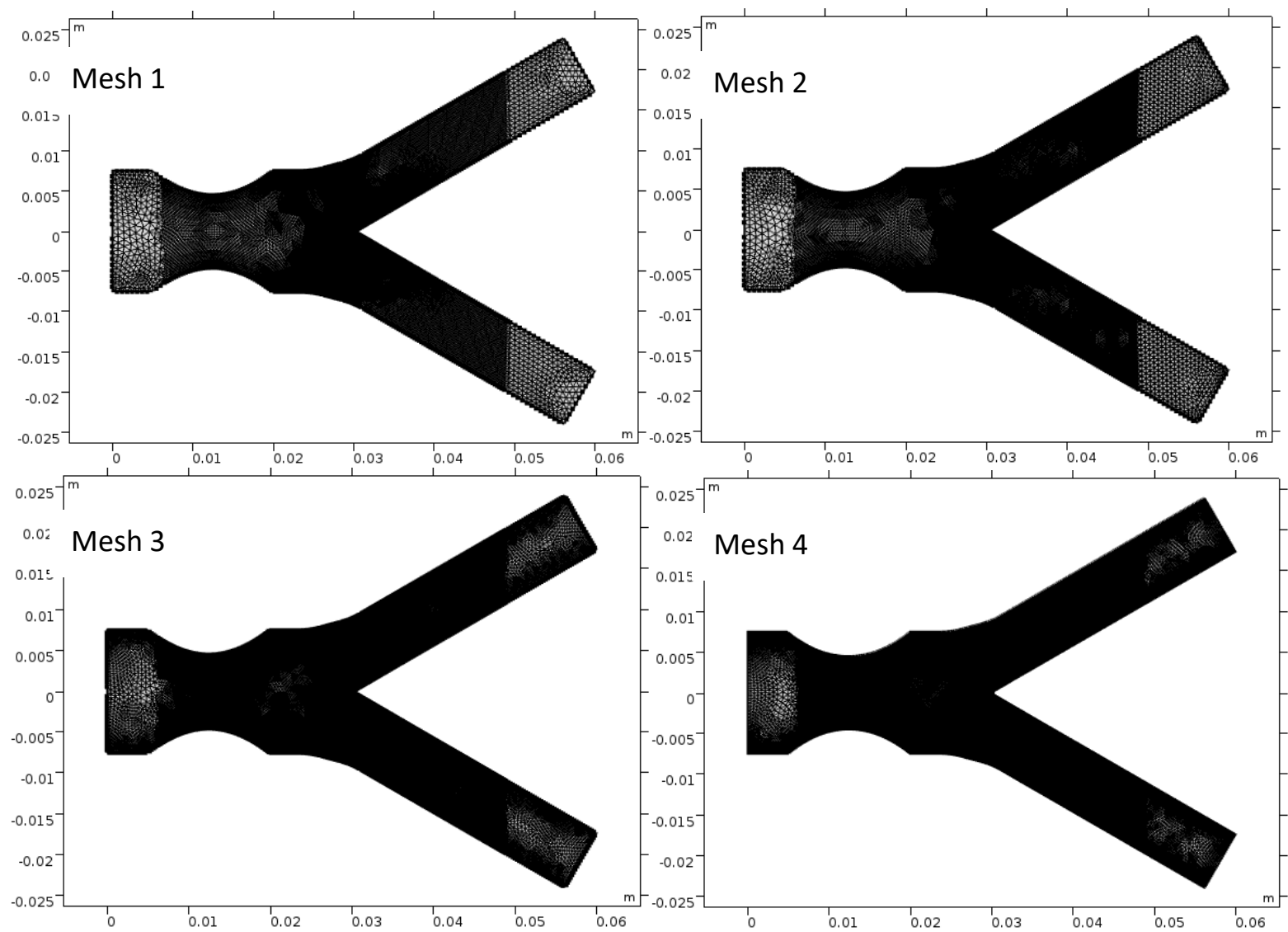

Fig. 2. Different unstructured triangular mesh elements

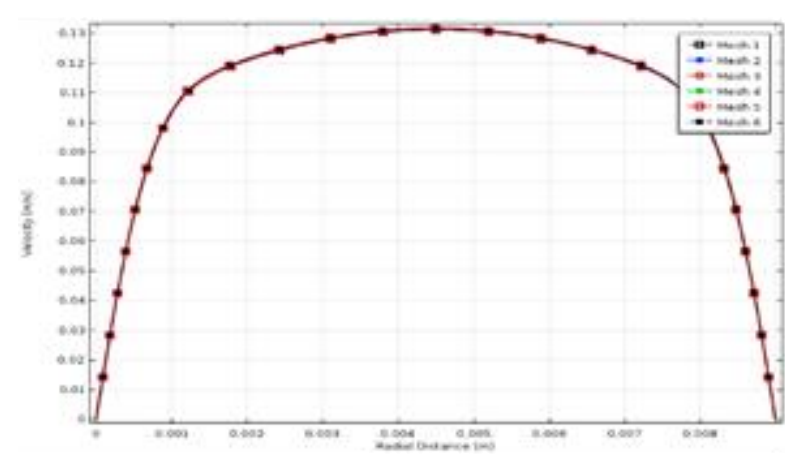

(a)

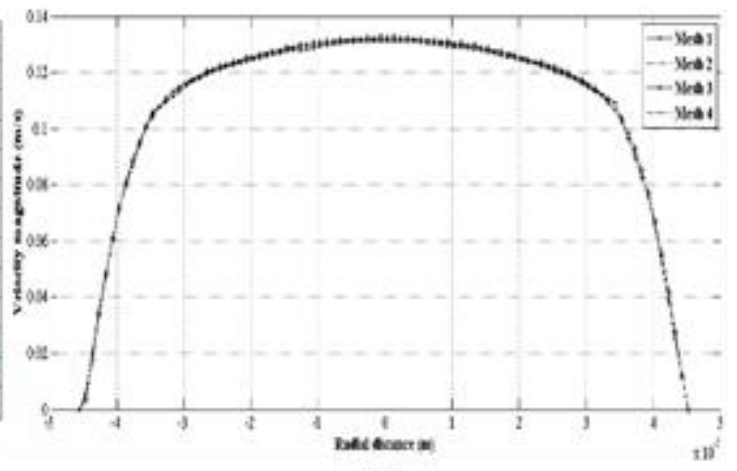

(b)

Fig. 3. Dimensional velocity profiles, $(\operatorname{Re}=300)$ from (a) COMSOL Multiphysics, and (b) MATLAB [17].

Table 2 consists of the respective maximum velocity obtained from COMSOL Multiphysics and MATLAB from [17] together with its coordinate. From the outcome, both results obtained agreed well with each other with a very small difference recorded approximately $0.0003 \mathrm{~m} / \mathrm{s}$ for the maximum velocity. 
Table 2

Comparison of maximum velocity and their coordinate

\begin{tabular}{lll}
\hline Software & Maximum velocity $(\mathrm{m} / \mathrm{s})$ & Coordinate $(x, y)$ \\
\hline COMSOL Multiphysics & 0.13487 & $\left(0.016154,3.1239 \times 10^{-5}\right)$ \\
MATLAB, [7] & 0.134610 & $\left(0.015,2.6418 \times 10^{-5}\right)$ \\
\hline
\end{tabular}
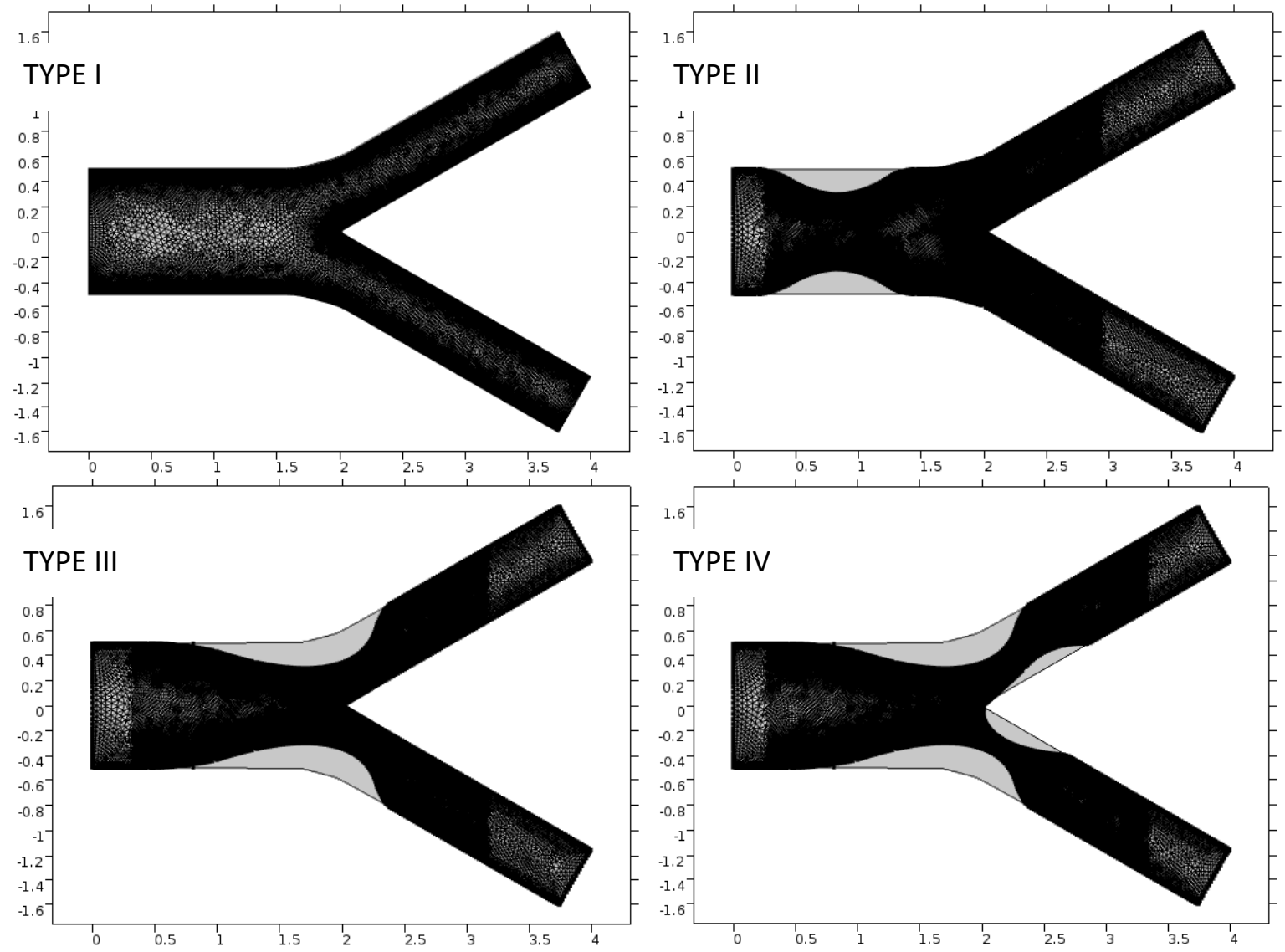

Fig. 4. Unstructured triangular mesh elements for TYPE I- TYPE IV

The same procedure of meshing is applied to four different types of the arterial bifurcation (TYPE I- TYPE IV) by considering blood as Newtonian and $R e=300$. Several attempts of mesh have been made for all type of geometry and only the stable mesh of them is selected and mentioned here, see Figure 4. The number of domain elements computed using COMSOL Multiphysics in present study are summarised in Table 3 followed together with its maximum velocity and coordinate.

Table 3

Mesh parameters computed in COMSOL Multiphysics and MATLAB

\begin{tabular}{llll}
\hline Type of bifurcated artery & Domain elements & Maximum velocity $(\mathrm{m} / \mathrm{s})$ & Coordinate $(x, y)$ \\
\hline TYPE I & 22739 & 0.80896 & $(0,0)$ \\
TYPE II & 23002 & 2.0135 & $(0.98373,0.012912)$ \\
TYPE III & 23420 & 2.3382 & $(2.2940,-0.29469)$ \\
TYPE IV & 23962 & 3.6433 & $(2.3565,0.43271)$ \\
\hline
\end{tabular}




\section{Results and Discussion}

The numerical computations have been performed in order to estimate the axial velocities at the mother and daughter artery and to visualize the streamlines as well as wall shear stress of the flow for different type of blood rheology.

\subsection{Streamlines Pattern for Different Type Model}

The streamline patterns that influence by the effect of different types of stenosis on the flow recirculation zones are illustrated from Figure 5 to Figure 7 for $n=0.639,1,1.2$. Obviously, the streamlines show a behaviour of normal undisturbed flow in the healthy artery (TYPE I). However, recirculation zone appears at the offset of the stenosis for TYPE II, TYPE III and TYPE IV. Clearly the reversed flow of the vortex reaches the edge of stenosis, it is unable to follow the curve of stenosis and to move away from the stenosis by changing its direction at the same time. For TYPE IV, clearly that the recirculation zone appears at upper and lower bifurcate artery with different pattern. In fact, the shape of stenosis in upper and lower bifurcate artery is slightly different and this affects the streamline solution greatly.
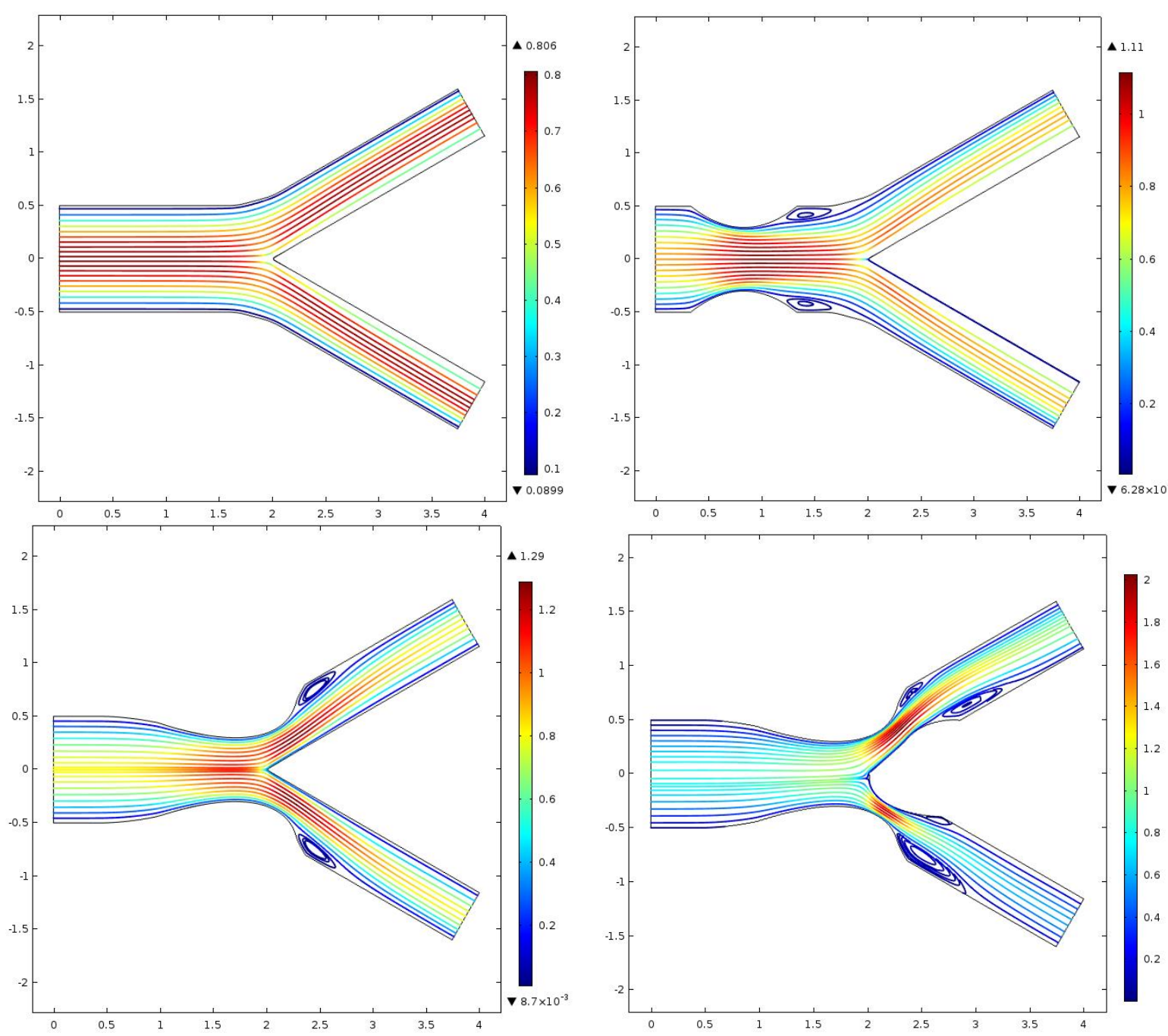

Fig. 5. Streamline patterns under the effect of different types of stenosis on the blood model with $n=0.639$ 
To further visualise and understanding of the blood behaviour, it is interesting to noted that the recirculation zones for TYPE II, TYPE III and TYPE IV are found to increase in sizes from shear-thinning $n=0.639$, Newtonian model $n=1$, to shear-thickening $n=1.2$ rheological. In fact, these results have good agreement with the experimental findings by [18] and the theoretical results in [19] and [20]. The flow reversal and recirculation zones are formed which might exposed an individual to a worsening effect of cardiovascular diseases. It is believed that the existence of flow recirculation in cardiovascular system can cause danger to the health of a person especially artherosclerosis patient since the blood is moving very slowly in this zone, [21].
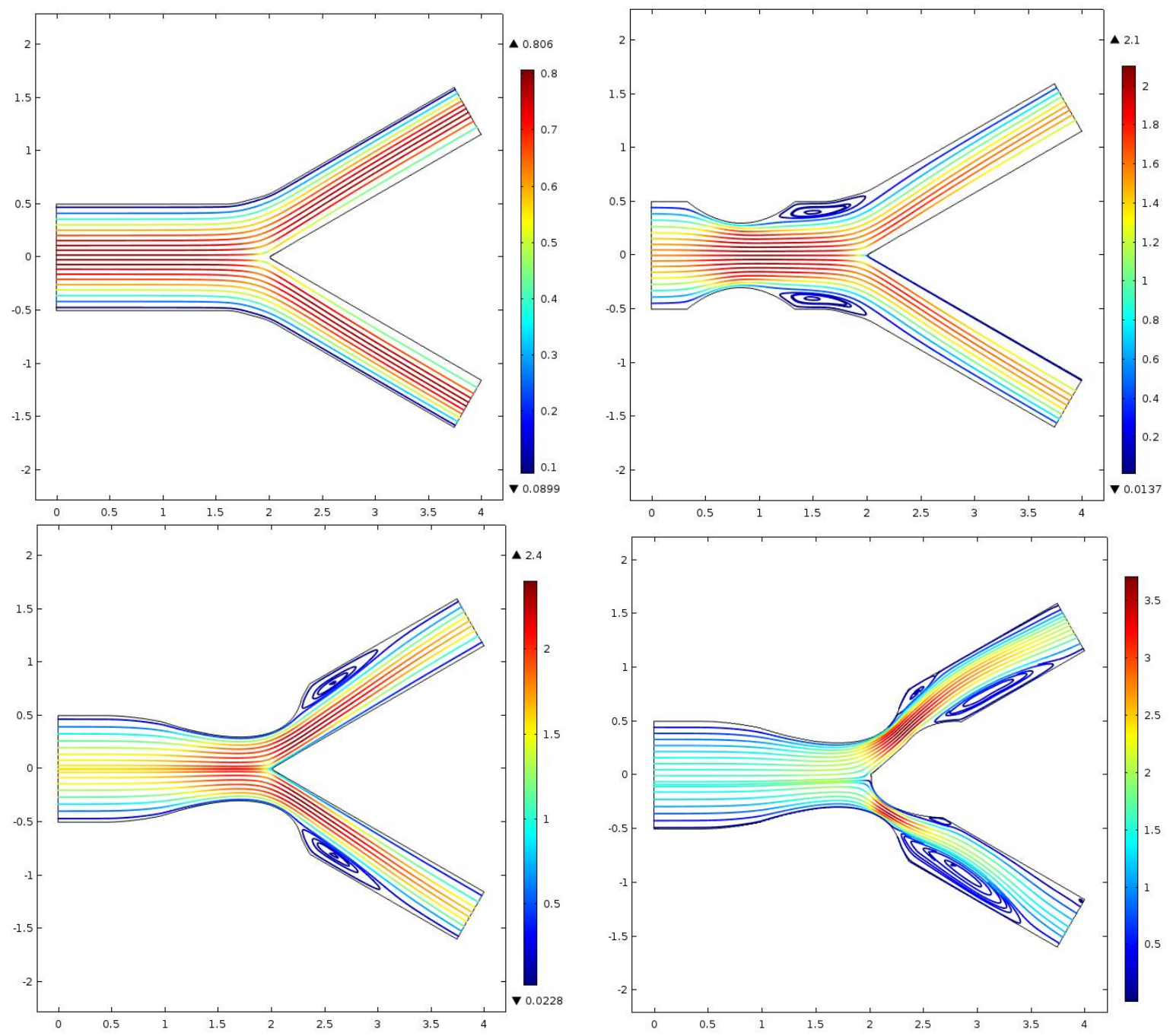

Fig. 6. Streamline patterns under the effect of different types of stenosis on the blood model with $n=1$ 

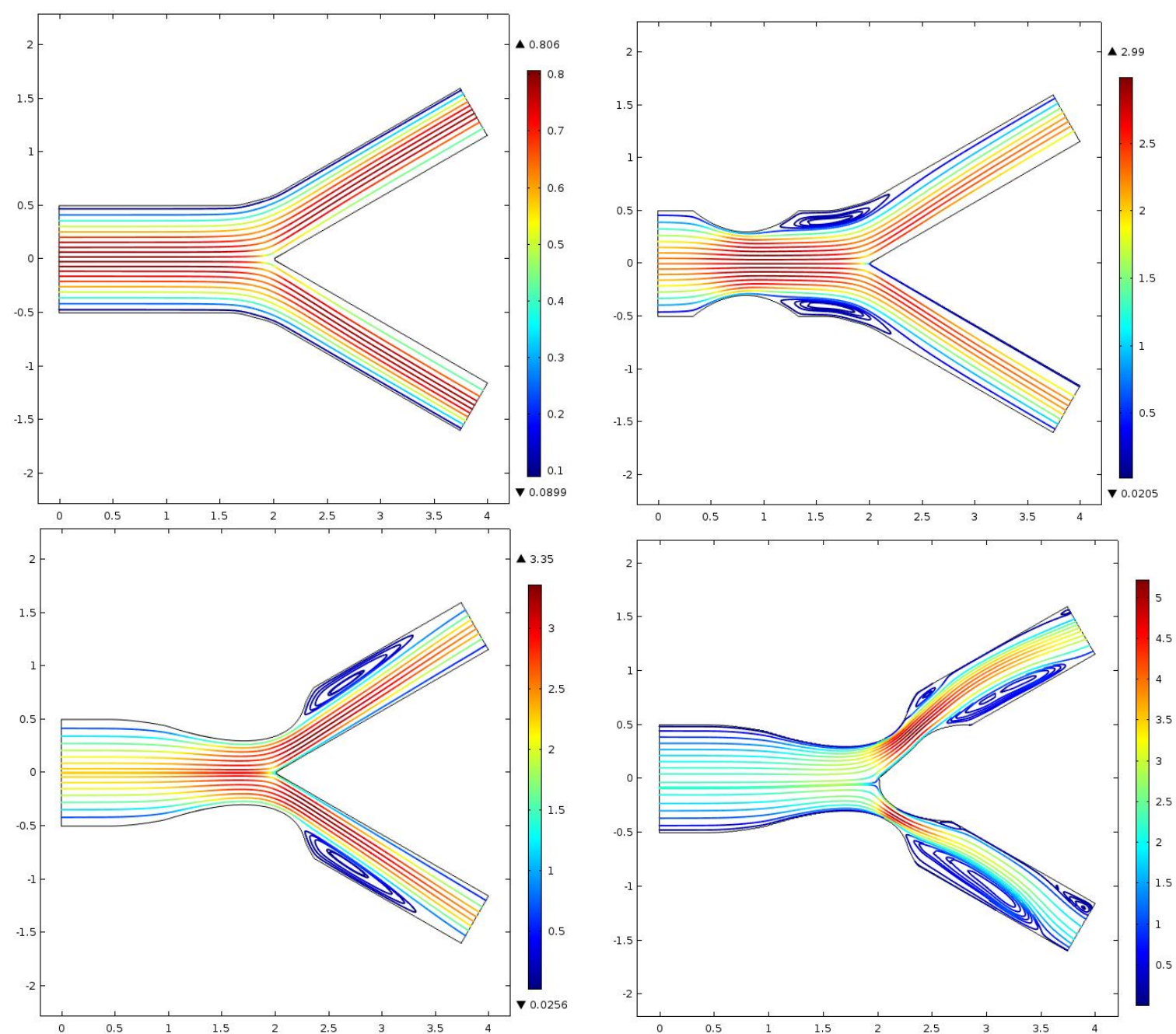

Fig. 7. Streamline patterns under the effect of different types of stenosis on the blood model with $n=1.2$

\section{Conclusion}

A mathematical model of a steady, laminar, and incompressible in four different types of stenotic bifurcated artery has been developed. In the present study, the bifucated artery consist of stenosis in the mother artery elongate into the bifurcation (daughter artery) in order to analyse blood flow characteristic in such unhealthy bifurcated artery has been discussed. The analysis has been carried out to investigate axial velocities at the mother and daughter artery and to visualize the streamlines of the flow for different type of blood rheology. The salient observations of the present theoretical study are listed below: example

i. Different types of stenosis give considerable effect to streamline pattern where backflow occurs and recirculation zones are formed at the downstream of stenosis.

ii. The type IV shows the most dangerous situation compare the others type so that in the future study that related to the stent need to carry out carefully.

\section{Acknowledgments}

The authors would like to acknowledge Ministry of Higher Education and Research Management Centre, Universiti Teknologi Malaysia for the financial support and the authors are also grateful for the support and hospitality of the Sydney Mathematical Research Institute (SMRI) and Griffith university during preparing this work. This work was supported by the Ministry of Higher Education 


\section{[R.J130000.7854.5F255 (FRGS Grant)] and Research Management Centre, Universiti Teknologi Malaysia (UTM) [Q.J130000.2554.21H48 (UTMFR Grant)].}

\section{References}

[1] Zaman, A., N. Ali, M. Sajid, and T. Hayat. "Effects of unsteadiness and non-Newtonian rheology on blood flow through a tapered time-variant stenotic artery." AIP advances 5, no. $3 \quad$ (2015): 037129. https://doi.org/10.1063/1.4916043

[2] Rabby, Mir Golam, Sumaia Parveen Shupti, and Md Molla. "Pulsatile non-newtonian laminar blood flows through arterial double stenoses." Journal of Fluids 2014 (2014). https://doi.org/10.1155/2014/757902

[3] lakovou, loannis, Lei Ge, and Antonio Colombo. "Contemporary stent treatment of coronary bifurcations." Journal of the American College of Cardiology 46, no. 8 (2005): 1446-1455. https://doi.org/10.1016/i.jacc.2005.05.080

[4] Lefèvre, Thierry, Yves Louvard, Marie-Claude Morice, Pierre Dumas, Christophe Loubeyre, Abdeljabbar Benslimane, Rajendra Kumar Premchand, Niels Guillard, and Jean-François Piéchaud. "Stenting of bifurcation lesions: classification, treatments, and results." Catheterization and cardiovascular interventions 49, no. 3 (2000): $274-283$. https://doi.org/10.1002/(SICl)1522-726X(200003)49:3<274::AID-CCD11>3.0.CO;2-N

[5] Pan, Manuel, Alfonso Medina, José Suárez de Lezo, Miguel Romero, Jose Segura, Pedro Martín, Javier Suárez de Lezo et al. "Coronary bifurcation lesions treated with simple approach (from the Cordoba \& Las Palmas [CORPAL] Kiss Trial)." The American journal of cardiology 107, no. $10 \quad$ (2011): 1460-1465. https://doi.org/10.1016/i.amjcard.2011.01.022

[6] Medina, Alfonso, José Suárez de Lezo, and Manuel Pan. "A new classification of coronary bifurcation lesions." Revista espanola de cardiologia 59, no. 2 (2006): 183-183. https://doi.org/10.1016/S18855857(06)60130-8

[7] Khader, Shah Mohammed Abdul, Adi Azriff, Cherian Johny, Raghuvir Pai, Mohammad Zuber, Kamarul Arifin Ahmad, and Zanuldin Ahmad. "Haemodynamics behaviour in normal and stenosed renal artery using computational fluid dynamics." Journal of Advanced Research in Fluid Mechanics and Thermal Sciences 51, no. 1 (2018): 80-90.

[8] Pedley, T. J. "The Fluid Mechanics of Large Blood Vessels,(1980)." CUP, Cambridge (1980). https://doi.org/10.1017/CBO9780511896996

[9] Berger, S. A., and Liang-Der Jou. "Flows in stenotic vessels." Annual review of fluid mechanics 32, no. 1 (2000): $347-$ 382. https://doi.org/10.1146/annurev.fluid.32.1.347

[10] Chen, Jie, and Xi-Yun Lu. "Numerical investigation of the non-Newtonian blood flow in a bifurcation model with a non-planar branch." Journal of biomechanics 37, no. 12 (2004): 1899-1911. https://doi.org/10.1016/j.jbiomech.2003.09.016

[11] Kumar Mandal, P., Santabrata Chakravarty, and Arabinda Mandal. "Numerical study of the unsteady flow of nonNewtonian fluid through differently shaped arterial stenoses." International Journal of Computer Mathematics 84, no. 7 (2007): 1059-1077. https://doi.org/10.1080/00207160701288881

[12] Mandal, Prashanta Kumar, Santabrata Chakravarty, Arabinda Mandal, and Norsarahaida Amin. "Effect of body acceleration on unsteady pulsatile flow of non-Newtonian fluid through a stenosed artery." Applied Mathematics and Computation 189, no. 1 (2007): 766-779. https://doi.org/10.1016/i.amc.2006.11.139

[13] Sarifuddin, Santabrata Chakravarty, and Prashanta Kumar Mandal. "Effect of asymmetry and roughness of stenosis on non-Newtonian flow past an arterial segment." International Journal of Computational Methods 6, no. 03 (2009): 361-388. https://doi.org/10.1142/S0219876209001887

[14] Yao, H., K. C. Ang, J. H. Yeo, and E. K. W. Sim. "Computational modelling of blood flow through curved stenosed arteries." Journal of medical engineering \& technology 24, no. $4 \quad$ (2000): $163-168$. https://doi.org/10.1080/03091900050163445

[15] Sarifuddin, Santabrata Chakravarty, and Prashanta Kumar Mandal. "Effect of asymmetry and roughness of stenosis on non-Newtonian flow past an arterial segment." International Journal of Computational Methods 6, no. 03 (2009): 361-388. https://doi.org/10.1142/S0219876209001887

[16] Chakravarty, Santabrata, and Prashanta Kumar Mandal. "An analysis of pulsatile flow in a model aortic bifurcation." International journal of engineering science 35, no. 4 (1997): 409-422. https://doi.org/10.1016/S00207225(96)00081-X

[17] Zain, Norliza Mohd, and Zuhaila Ismail. "Modelling of Newtonian blood flow through a bifurcated artery with the presence of an overlapping stenosis." Malaysian Journal of Fundamental and Applied Sciences 13, no. 4-1 (2017): 304-309. https://doi.org/10.11113/mifas.v13n4-1.866

[18] Ahmed, Saad A., and Don P. Giddens. "Velocity measurements in steady flow through axisymmetric stenoses at moderate Reynolds numbers." Journal of biomechanics 16, no. 7 (1983): 505-516. https://doi.org/10.1016/0021$\underline{9290(83) 90065-9}$ 
[19] Middleman, Stanley. Modeling axisymmetric flows: dynamics of films, jets, and drops. Academic Press, 1995. https://doi.org/10.1016/B978-012494950-8/50002-X

[20] Mustapha, Norzieha, Prashanta K. Mandal, Peter R. Johnston, and Norsarahaida Amin. "A numerical simulation of unsteady blood flow through multi-irregular arterial stenoses." Applied Mathematical Modelling 34, no. 6 (2010): 1559-1573. https://doi.org/10.1016/i.apm.2009.09.008

[21] Jamali, Muhammad Sabaruddin Ahmad, and Zuhaila Ismail. "Simulation of Heat Transfer on Blood Flow through a Stenosed Bifurcated Artery." Journal of Advanced Research in Fluid Mechanics and Thermal Sciences 60, no. 2 (2019): 310-323. 